\title{
Aprovechamiento de residuos orgánicos para la generación de biogás
}

\section{Use of organic waste for the generation of biogas}

\author{
GARCÍA-MAGALLANES, Gabriel †, OSORIO-CANUL, Marvin, HERRERA-LUGO, Angélica y \\ NOVELO-MOO, Thelma*
}

Universidad Tecnológica Metropolitana-Mérida.

ID $1^{\mathrm{er}}$ Autor: Gabriel, Garcia Magallanes / ORC ID: 0000-0002-2091-6433

ID $1^{\text {er }}$ Coautor: Marvin, Osorio Canul / ORC ID: 0000-0002-6129-2559

ID $2^{\text {do }}$ Coautor: Herrera Lugo, Angélica / ORC ID: 0000-0001-8066-8956, CVU CONACYT ID: 27295

ID $3^{\text {er }}$ Coautor: Thelma, Novelo-Moo / ORC ID: 0000-0002-6383-9933, CVU CONACYT ID: 458937

DOI: $10.35429 / J R E .2019 .10 .3 .23 .27$

Recibido 03 de Julio, 2019; Aceptado 28 Septiembre, 2019

\section{Resumen}

En el país la información sobre la energía renovable está muy dispersa y el nivel de contaminación a causa de desechos de animales callejeros; como los perros o gatos, que contaminan el aire y causan enfermedades va en aumento. Dicha acumulación es generada principalmente por la disposición de lugares no ideales y ausencia de manejo de estos residuos; el problema se acrecienta en lugares donde la cantidad de canes aumenta considerablemente como son las calles, los refugios y lugares de adopción, puesto que la tasa de generación de heces caninas es mucho mayor. Se realizó un biodigestor el cual produce biogás por medio de la digestión anaerobia a partir de heces caninas con la finalidad de promover las energías alternas y así poder reducir el alto índice de contaminación e insalubridad que las heces generan al quedar expuestas a la intemperie. Este biodigestor permite realizar pruebas a pequeña escala con las heces caninas, ya que sus condiciones de operación están contempladas a la zona geográfica.

\section{Biodigestor, Biogás, Heces caninas}

\begin{abstract}
In our country, information on renewable energy is widely dispersed and the level of contamination of stray animals; like dogs and cats, they pollute the air and cause diseases in the increase. This accumulation is generated by the disposition of the non-ideal places and the absence of handling of these residues. The problem grows in places where the number of canes increases such as streets, shelters and places of adoption, the rate of generation of canine hinas is much higher. A biodigester was built which produces biogas through anaerobic digestion from canine excrement with the aim of promoting alternative energies and thus reducing the high level of contamination and unhealthiness that crop feces by being exposed to outdoor. This biodigester allows small-scale tests with canine feces, since its operating conditions are contemplated in the geographical area.
\end{abstract}

Biodigester, Biogas, Dog excrement

Citación: GARCÍA-MAGALLANES, Gabriel, OSORIO-CANUL, Marvin, HERRERA-LUGO, Angélica y NOVELOMOO, Thelma. Aprovechamiento de residuos orgánicos para la generación de biogás. Revista de Energías Renovables. 2019. 3-10: $23-27$

\footnotetext{
* Correspondencia del Autor (Correo electrónico: thelma.novelo@ hotmail.com)

$\dagger$ Investigador contribuyendo como primer autor.
} 


\section{Introducción}

En las calles de la ciudad de Mérida es común encontrarse con un perro callejero o decena de ellos, todo depende de la zona por donde te encuentres. México es el país con mayor población de perros en Latinoamérica, pero menos de la mitad de ellos tiene hogar o refugio. Según datos de la Secretaría de Salud existen alrededor de 22 millones de canes, de los cuales más de 10 millones viven en la calle. "Aunque no se cuenta con una cifra exacta, se calcula que el $30 \%$ de los perros tiene dueño, el $30 \%$ es comunitario y el $40 \%$ está en la vía pública", ha informado Carlos Esquivel Lacronix, jefe de vinculación en la Facultad de Medicina Veterinaria y Zootecnia de la UMAN (Rodríguez, 2012).

En el estado de Yucatán la población canina genera una cantidad considerable de heces caninas procedentes de las veterinarias y refugios animales que pueden ser utilizadas para la producción de biogás pero que no se aprovechan adecuadamente, por el contrario, la acumulación de estos residuos orgánicos se está convirtiendo en un problema de salud pública. La costumbre que generalmente la sociedad tiene al sacar a sus perros a pasear es el dejar el excremento tirado en la calle, lo cual genera un gran impacto ambiental de manera negativa a causa de las bacterias que estas mismas contienen (Moreno, 2011).

La población que si recolecta las heces de sus animales, las pone en bolsas de plástico y generalmente estos residuos tienen un solo destino: se envían al relleno sanitario que se encuentra en las afueras de la ciudad de Mérida. El enviar las heces a este relleno llega a ser muy insalubre tanto para los operarios como para los habitantes ya que las bolsas en que se transportan las heces, pesan mucho y se pueden reventar, al llegar estos desechos al relleno sanitario se entierran, lo cual es un gran error puesto que las heces enterradas generan malos olores y lixiviados ácidos que no son aptos para la tierra. La reutilización de esta materia puede ser una alternativa ya que se puede convertir en una energía alterna la cual pueda ser beneficiosa no solo con el medio ambiente si no de igual manera para la sociedad misma reduciendo un alto porcentaje de contaminación al momento de quemarla para su utilización.
Molina (2008) reporta que en el año 1776 el científico italiano Alessandro Volta, descubrió que el principal compuesto del gas natural era metano, haciendo una observación en los pantanos de formaciones de burbujas y al reventar desprendían un olor fétido y también que estas eran flamables. Pero solo hasta 100 años después se descubrió el origen microbiológico que causaba la formación de metano. Para 1906 el científico Soehngen descubre que el metano estaba formado de hidrogeno y dióxido de carbono y a su vez, describe los primeros organismo que participan en la formación de metano.

En 1940, se construyen las primeras plantas de biogás por familias prósperas en China, después de 1945, finalizando la segunda guerra mundial se construyeron cerca de 40 biodigestores, pero su desarrollo se frenó por los combustibles fósiles. Sin embargo, para la década de los 70's se vuelve a reiniciar la contribución de biodigestores debido a la crisis de petróleo, pero los problemas técnicos, baja producción de gas y alta inversión este desarrollo se frenó a fines de los 80’s (Ostos, 2013).

Hay registros que muestran la existencia de 563 sistemas de biodigestión de acuerdo a los 142 Project Design Document (PDD) encontrados en los registros digitales de la UNFCCC (United Nations Framework Convention on Climate Change), relacionados con la reducción de emisiones de metano en el sector agropecuario en México. En los últimos años muchas unidades han incorporado sistemas de biodigestión dentro de sus procesos productivos, el fin concreto de la instalación de ésta tecnología fue en un principio la comercialización de Bonos de Carbono, por la reducción de emisiones de Gases de Efecto Invernadero (GEI). En la actualidad se han visualizado una diversidad de usos $y$ aplicaciones de estos sistemas, tales como la reducción de contaminantes en las descargas de aguas residuales de las unidades pecuarias y la generación de energía eléctrica (Velazquez, 2016)

\section{Biodigestión anaerobia}

Todos los residuos orgánicos son adecuados para ser fermentados anaeróbicamente (no importa el tipo de materia prima, siempre y cuando este sea orgánico). 
Las bacterias consumen el carbono y el nitrógeno que se encuentra dentro del biodigestor y como resultado tenemos la obtención de biogás o gas de los pantanos. En un biodigestor se producen tres tipos de reacciones de digestión anaeróbica la cual es necesaria para poder obtener metano, como se muestra en la figura 1.

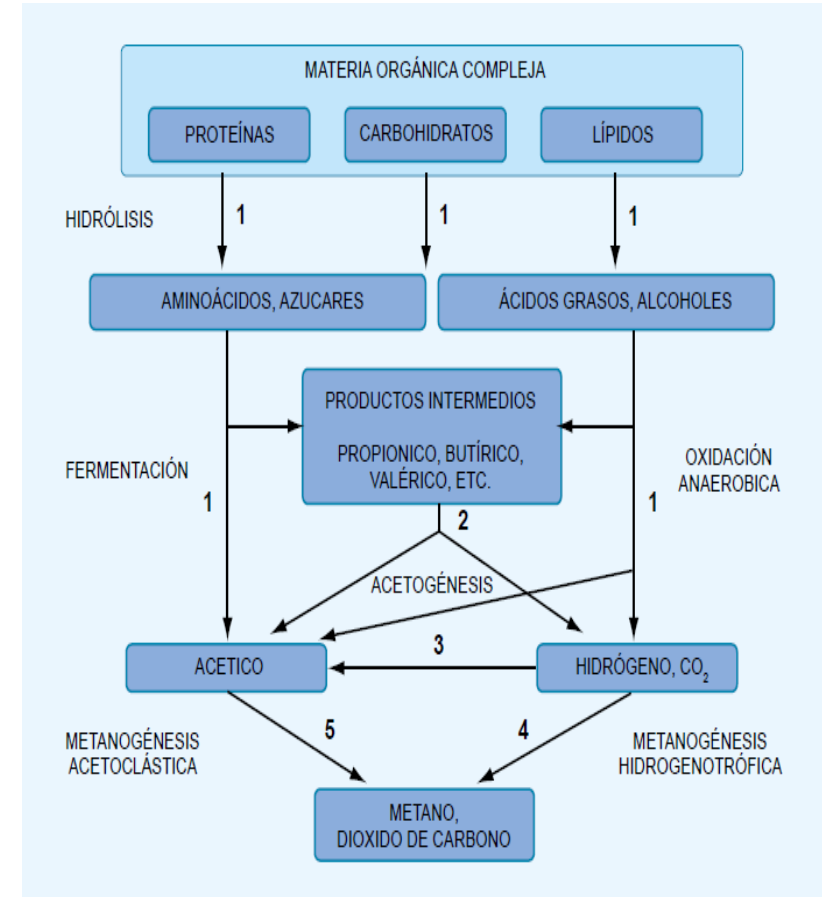

Figura 1 Esquema de reacciones de la digestión anaeróbica (Moreno, 2011)

La materia prima se mezcla con agua, se cierra la entrada de carga y se comienza el proceso de digestión anaeróbica. Al pasar un tiempo, determinado por las condiciones de temperatura y características del sustrato principalmente, empiezan a producirse gases como producto de la digestión. Estos gases se van acumulando en la parte superior del biodigestor. Junto a la entrada de carga tenemos una válvula para dar salida a los gases y poder hacer uso de ellos. En la parte inferior del biodigestor tenemos un extractor de lodos para poder limpiar el biodigestor después de un determinado tiempo.

Una de las características del sustrato es la razón de carbono a nitrógeno $(\mathrm{C} / \mathrm{N})$ y representa la proporción de los dos elementos. Una razón $\mathrm{C} / \mathrm{N}$ de 30 (30 veces más carbono que nitrógeno) permitirá que la digestión se lleve a cabo a un ritmo óptimo, a condición de que las otras condiciones sean favorables. En cuanto a la temperatura, para que las bacterias digestivas trabajen con la mayor eficiencia, lo mejor es una temperatura de $36^{\circ} \mathrm{C}$.
La producción de gases puede producirse en dos gamas de temperaturas: de 29,4 a $40,5^{\circ} \mathrm{C}$ y de 48,8 a $60^{\circ} \mathrm{C}$. Hay diferentes grupos de bacterias productoras de ácidos y metano que medran en cada una de esas gamas diferentes. A las activas en la gama más alta se las llama bacterias termofílicas (Macola, 1995). Con relación al $\mathrm{pH}$, durante la fase inicial ácida, que puede durar 2 semanas, el $\mathrm{pH}$ puede bajar a 6 o menos, mientras que se produce una gran cantidad de $\mathrm{CO} 2$. Conforme prosigue la digestión se produce menos $\mathrm{CO} 2$ y más metano y el $\mathrm{pH}$ se eleva lentamente hasta llegar a un valor entre 7 y 8 (básico).

\section{Metodología}

\section{Construcción del biodigestor}

Para la determinación del prototipo a pequeña escala se realizaron análisis preliminares en $\mathrm{u}$ modelo de 20 litros cuyos resultados se emplearon para escalar a volúmenes mayores. El primer prototipo de biodigestor que se realizó fue con una cubeta de 20L, contaba con una llave de $1 / 2$ pulgada para verificar si había producción o indicios de metano dentro del tanque, del otro extremo se le coloco una llave de 1" para la extracción completa del producto y poder realizar las pruebas correspondientes (figura 2).

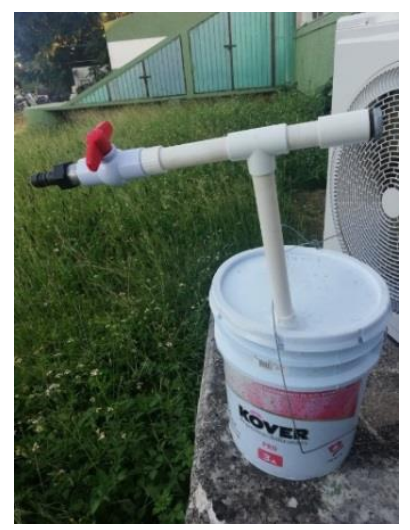

Figura 2 Primer prototipo de biodigestor

Una vez comprobada las condiciones de las biodigestión anareobia de heces caninas, así como los requisitos físicos de materiales en el reactor, se procedió a la etapa de escalamiento: el segundo prototipo biodigestor se construyó con un tanque de plástico cilíndrico cuasi regular de $0.54 \mathrm{~m}$ de diámetro tanto inferior como superior con una altura de $0.87 \mathrm{~m}$, lo que da una capacidad de 200 litros (figura 3 ). 
En su parte superior tiene colocado una entrada de carga con una tapa roscada y una salida del biogás mediante una válvula y manguera de gas. En la parte inferior lateral tiene una válvula de 1" para la extracción de lodos.

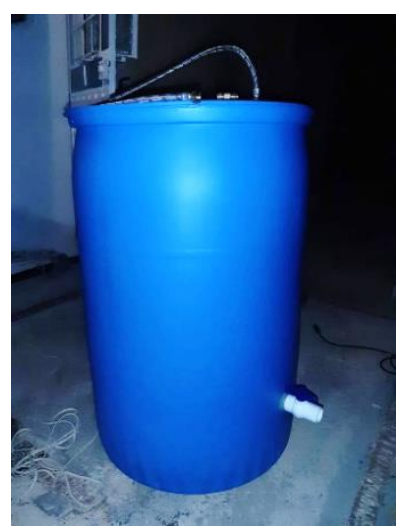

Figura 3 Segundo prototipo de biodigestor

\section{Resultados}

Se realizaron las pruebas preliminares utilizando $3.0 \mathrm{Kg}$ de excremento canino (figura 4) y $91 \mathrm{de}$ agua para levar la humedad del sustrato a las condiciones ideales de fermentación anaerobia. Cinco semanas después a las se revisó la producción y se recolecto el biogás dentro un globo para poder realizar la prueba en él, se notó que al exponer el biogás al encendedor este se apagó y se escuchó un pequeño sonido de combustión, al dejar salir el biogás para realizar las pruebas este desprendió un olor fétido característico de la fermentación anaerobia.

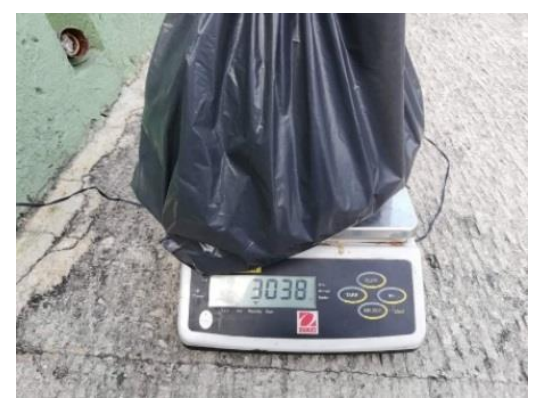

Figura 4 Excremento canino

Para otra prueba preliminar se introdujeron las mismas cantidades de carga de excremento y de agua, posterior a esto se verifico el sello de la tapa y notamos que en 24 horas ya había comenzado la generación de metano. El olor era altamente fuerte a pesar de estar completamente sellado el biodigestor.
Posterior a esto nos percatamos que al sacar la carga el biodigestor después de nueve semanas tuvo un cambio en cuestión de la densidad del sustrato, hubo una separación de fases indicando una fermentación completa, pues en la parte inferior se encontraban los lodos y en la parte superior se observó una fase líquida, sin sólidos que indicaran alguna fase de la biodigestión, además en la salida de gases ya no se apreciaba la presencia de biogás.

\section{Conclusiones}

El prototipo de biodigestor permitió realizar a pequeña escala pruebas con las heces caninas. Las condiciones de alimentación del sustrato y de operación del biodigestor permitieron la producción de biogás a partir de una semana de trascurrida la alimentación y durante las 5 semanas siguientes. Este modelo de biodigestor puede emplearse en refugios y casas habitación que tengan una como parte de sus desechos la generación de heces caninas. El biogás generado puede aprovecharse para producir por el mismo usuario del biodigestor obteniéndose de esta manera dos beneficios, menos contaminación y energía.

\section{Referencias}

Beily, M.E., Morici, G., Crespo, D., Schapiro, J. (2019) Biochemical methane potential of sheep manure: Focus in pathogen removal Journal of Agriculture and Veterinary Science. 12, 24-31.

Molina, S. (2008). Historia del Biogás. Recuperado el 2019 de 01 de 10, de http://porcinos.blogspot.com/2006/01/historiadel-bio-gas_113857323502124249.html

Martínez, S. G. (2019). Producción de Biogás a partir de la fracción orgánica de residuos sólidos urbanos (FORSU). Gaceta Instituto de Ingeniería, UNAM, 1(135), 15-17.

Moreno, M. T. (2011). Manual del biogás. Santiago , Chile: MINENERGIA; PNUD; FAO; GEF.

Ostos T. J. P., 2013. Plan de Negocios para la Empresa Nacional de Digestores. Escuela Colombiana de Carreras Industriales Bogotá D.C. Flotats, X., Campos, E., Bonmatí, A. (1997) Aprovechamiento energético de recursos ganaderos. 3er curc dénginyeria ambiental. Universitat de Lleida Lérida. 
Red Mexicana de Bioenergía. (s.f.). Red Mexicana de Bioenergía. Recuperado el 11 de 12 de 2018, de http://rembio.org.mx/areastematicas/biogas/

Rodríguez, L. E. (27 de 09 de 2012). Ciencia UNAM. Obtenido de Ciencia UNA. 14 de Marzo de 2019. Sitio web: http:// ciencia .unam.mx/leer/109/Proponen_solucion_al_prob lema_de_los_perros_callejeros

Textos científicos. (2005) Factores Que Afectan La Producción De Gas. 04 De octubre de 2019. Sitio web: http://www.textoscientificos.com/ energia/biogas/factores

Textos científicos. (2005) Fermentación Anaeróbica. 24 de septiembre de 2019. Sitio web: http://www.textoscientificos.com/ energia/ fermentacion

Velazquez, C. A. (09 de 2016). Uso de biodigestores en la industria pecuaria. Obtenido de Uso de biodigestores en la industria pecuaria.: http://ri.uaemex.mx/bitstream/handle/ 20.500.11799/66337/TESINA-CAV-1016.pdf? sequence $=1$

Wang, C.; Zhang, Y.; Zhang, L.; Pang, M. (2016). Alternativa policies to subsidize rural house hold biogas digesters. Energy Policy. Vol. 93. Núm. 187-195 